\title{
Propulsion Control Experience Used in the Highly Integrated Digital Electronic Control (HIDEC) Program
}

Lawrence P. Myers and Frank W. Burcham, Jr.

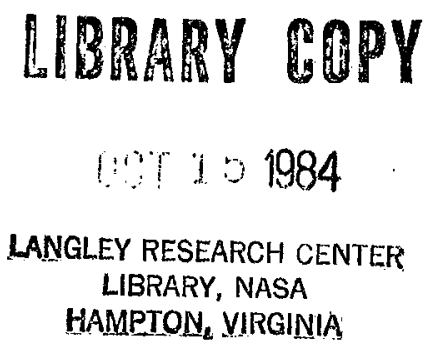


NASA Technical Memorandum 85914

\section{Propulsion Control Experience Used in the Highly Integrated Digital Electronic Control (HIDEC) Program}

Lawrence P. Myers and Frank W. Burcham, Jr.

Ames Research Center, Dryden Flight Research Facility, Edwards, California 93523

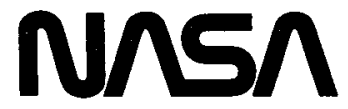

National Aeronautics and

Space Administration

Ames Research Center

Dryden Flight Research Facility

Edwards, California 93523 
. 


\title{
Propulsion Control Experience Used in the Highly Integrated Digital Electronic Control (HIDEC) Program
}

\author{
Lawrence P. Myers and Frank w. Burcham, Jr. \\ NASA Ames Research Center \\ Dryden Flight Research Facility \\ Edwards, California
}

\section{ABSTRACT}

The highly integrated digital electronic control (HIDEC) program will integrate the propulsion and flight control systems on an F-15 airplane at NASA Ames Research Center's Dryden Flight Research Facility. Ames-Dryden has conducted several propulsion control programs that have contributed to the HIDEC program. The digital electronic engine control (DEEC) flight evaluation investigated the performance and operability of the F100 engine equipped with a fullauthority digital electronic control system. Investigations of nozzle instability, fault detection and accommodation, and augmentor transient capability provided important information for the HIDEC program. The F100 engine model derivative (EMD) was also flown in the F-15 airplane, and airplane performance was significantly improved. A throttle response problem was found and solved with a software fix to the control logic. For the HIDEC program, the F100 EMD engines equipped with DEEC controls will be integrated with the digital flight control system. The control modes to be implemented are an integrated flightpath management mode and an integrated adaptive engine control system mode. This paper discusses the engine control experience that will be used in the HIDEC program.

OVER THE LAST SEVERAL YEARS, the advantages of integration between components of a propulsion system and between the propulsion system and the airframe have been shown. The digital propulsion control programs conducted at NASA Ames Research Center's Dryden Flight Research Facility are shown in figure 1. The USAF/NASA integrated propulsion control system (IPCS) program $(1)$ * integrated the engine and inlet controls on the F-111 airplane and demonstrated significant improvements. The NASA Cooperative Control Program on the $\mathrm{YF}-12 \mathrm{C}$ airplane (2),

\footnotetext{
* Numbers in parentheses designate references at end of paper.
}

which integrated the inlets, autopilot, autothrottle, and navigation system, was so successful that the USAF is now equipping the SR-71 aircraft fleet with a similar system. At the completion of these programs, NASA conducted a study called propulsion flight control integration technology (PROFIT) (3) and a follow-on program calied integrated research aircraft technology (INTERACT) (4). These studies identified the benefits that can be gained by integration of propulsion and flight control systems on existing aircraft and found these gains to be substantial. The INTERACT study has been extended to examine the addition of the augmented deflector exhaust nozzle (ADEN) to the $\mathrm{X}-29$ forward-swept wing demonstrator airplane and the propulsion-flight control integration requirements and benefits. A digital engine control system was also implemented on the highly maneuverable aircraft technology (HiMAT) remotely piloted research vehicle, which improved the capability of that airplane (5).

NASA, in conjunction with the USAF, has conducted a flight evaluation of the digital electronic engine control (DEEC) system on an F-15 airplane (6). The DEEC provides a full-authority digital control capability for the F100 engine in the F-15 airplane, and results in significant performance and operability improvements. As a follow-on program to the DEEC evaluation, the F100 engine model derivative (EMD) was also flown in the F-15 airplane (7). The F100 EMD engine has 15 percent more thrust than the standard F100 engine and is equipped with a DEEC.

As a result of the INTERACT study results, and with the experience derived from the DEEC and EMD evaluations, Ames-Dryden, in cooperation with other government agencies, is conducting a program called highly integrated digital electronic control (HIDEC) (8). This program will. develop and evaluate new digital engine control technology that is integrated with the airplane's digital flight control system. This paper discusses the propulsion experiences gained from the INTERACT, DEEC, and EMD programs that have contributed to the HIDEC program and describes the HIDEC program and its expected benefits. 


\section{INTERACT STUDY RESULTS}

The INTERACT studies examined the benefits of integrated propulsion and flight control systems on the F-15, F-18, and F-111 airplanes. Results showed that the control mode with the largest performance payoff was the adaptive engine control system (ADECS) in which airframe data is used to allow the engine to operate at higher performance levels (uptrim) at times when the inlet distortion is low and the full engine stall margin is not required. The ADECS mode can also be used to obtain additional engine stall margin (downtrim) during certain flight manuevers, such as a STOL landing rollout with reverse thrust where reingestion could cause an engine stall, or for extreme attitude flight such as that which could be used for fuselage pointing.

The second most beneficial mode identified in the INTERACT study was the integrated flightpath management mode. In this mode, the pilot could input the desired end points, and the integrated logic would provide the optimum flightpath and throttle setting. The pilot could follow a display or the system commands could be input directly to the flight controls and throttles.

\section{HIDEC PROGRAM}

The objective of the HIDEC program is to demonstrate and evaluate the improvements in performance and mission effectiveness that result from integration of the propulsion and flight control systems. The features of the HIDEC system are shown in figure 2. Digital control of the F100 EMD engines can be accomplished with the DEEC systems. The digital electronic flight control system has been installed on the $F-15$ airplane and will be used to provide the flight control system inputs. A digital interface and bus control unit will allow the various systems to communicate with each other. A telemetry uplink from ground-based computers will also be available. The HIDEC system is described in reference 8 and is discussed in greater detail in THE HIDEC SYSTEM section of this paper.

\section{DESCRIPTION OF EQUIPMENT}

The equipment used in the DEEC, EMD, and HIDEC programs is described in this section. AIRPLANE - The NASA F-15 airplane is being used for the HIDEC program. It is a highperformance, air-superiority fighter aircraft with excellent transonic maneuverability and a maximum Mach capability of 2.5. It is powered by two afterburning turbofan engines.

ENGINES - The F100 engines are used in the DEEC, EMD, and HIDEC programs. The F100 is a low-bypass ratio, twin-spool, afterburning turbofan engine (shown in fig. 3). The three-stage fan is driven by a two-stage, low-pressure turbine. The 10-stage, high-pressure compressor is driven by a two-stage turbine. The engine incorporates compressor inlet variable vanes (CIVV) and rear compressor variable vanes (RCVV) to achieve high performance over a wide range of power settings; a compressor bleed is used only for starting. Continuously variable thrust augmentation is provided by a mixed flow aftexburner and a variable area convergent-divergent nozzle.

For the DEEC program, the F100-PW-100 engine was used. It incorporated a 5-segment augmentor, a prototype DEEC system, and a static pressure probe (PS2) on the engine hub. The F100 EMD incorporates a largex fan, improved materials in the hot section, a 16-segment augmentor, and a later-generation DEEC, resulting in a 15-percent increase in thrust. The F100 EMD engines are scheduled for use in the HIDEC program.

DEEC - The DEEC system is a full-authority, engine-mounted, fuel-cooled digital electronic control system that performs the functions of the standard F100 engine hydromechanical unified fuel control and the supervisory digital electronic engine control. The DEEC consists of a single-channel digital controller with selective input-output redundancy, and a simple hydromechanical backup control (BUC). The DEEC system is functionally illustrated in figure 4. It receives inputs from the airframe through throttle position power lever angle (PLA) and Mach number (M), and from the engine through pressure sensors (PS2, PB, and PT6M), temperature sensors (TT2 and FTIT), rotor speed sensors ( $N 1$ and $\mathrm{N} 2$ ), and the ultraviolet flame sensor, the light-off detector (LOD). It also receives feedbacks from the controlled variables through position feedback transducers indicating variable vane (CIVV and RCVV) positions, metering valve positions for gas-generator fuel flow (WFGG), augmentor core and duct fuel flow, segment-sequence valve position, and exhaust nozzle position (AJ). Dual sensors and position transducers are used as shown in figure 4 to achieve redundancy in key parameters.

The input information is processed by the DEEC computer to schedule the variable vanes (CIVV and RCVV), position the compressor start bleeds, control gas-generator and augmentor fuel flows, position the augmentor segment-sequence valve, and control exhaust nozzle area. Redundant coils are present in the torque motor drivexs for all of the actuators.

DEEC Logic - The DEEC logic provides openloop scheduling of CIVV, RCVV, start bleed position, and augmentor controls. The DEEC incorporates closed-loop control logic for control of WFGG and AJ. With this closed-loop logic, it is possible to eliminate the need for periodic trimming and improve performance. The two main closed loops are shown in figure 5. The top part of the figure shows the total airflow logic in which WFGG is controlled to maintain the scheduled fan speed and hence, airflow. Prom portional-plus-integral control is used to match the $\mathrm{N} 1$ request to the sensed $\mathrm{N} 1$. Limits of core rotor speed (N2), fan turbine inlet temperature (FTIT), and burner pressure (PB) are maintained. The airflow loop is used for all throttle settings. 
The engine pressure ratio (EPR) 10op is shown in the lower part of figure 5. The requested EPR is compared with the EPR, based on fan inlet total pressure (PT2) and turbine discharge total pressure (PT6M), and, using proportional-plus-integral control, the nozzle is modulated to achieve the requested EPR. The EPR control loop is only active for intermediate power operation and augmentation. At lower power settings, a scheduled nozzle area is used. With the closed-loop airflow and EPR logic, the DEEC control is capable of automatically compensating for engine degradation. EPR is directly related to thrust, so the DEEC can maintain an engine at a desired thrust level. As the engine degrades, the FTIT that is required to achieve the scheduled EPR increases until it reaches its limit. The DEEC then operates the engine on the FTIT limit.

The PT2 signal is derived from the PS2 measurement. A PT2 to PS2 relationship has been determined from previous wind tunnel and flight tests.

Augmentor Logic - Augmentor fuel distribution is handled by a segment-sequencing valve (fig. 4). The segment-sequencing valve handles the sequencing and distribution of metered flow, and the separate core and duct fuel-flow metering valves control the flow to the segments. For the DEEC flight evaluation, the 5-segment augmentor was used; its logic is described in reference 6 . For the F100 EMD flights, the 16-segment augmentor was used; its logic is discussed in reference 7 .

For the last phase of the DEEC flight evaluation, and all of the F100 EMD flights; a lightoff detector (LOD) was installed. This ultraviolet sensor had an output that was proporim tional to flame intensity (LOD counts). With the LOD, additional logic was incorporated to automatically detect augmentor blowouts and to attempt relights without pilot action. Once a blowout was detected, the DEEC logic turned off the augmentor fuel, performed an LOD self check, and then reinitiated the augmentor sequence (called a PLA recycle). The LOD was also used after the segment 1 light was detected. A certain minimum flame strength (in terms of LOD counts) was required before the sequence would proceed to the additional segments. Up to three PLA recycles were allowed without pilot action. DEEC Fault Detection and Accommodation (FDA) - The DEEC system is a single-channel digital controller with selective redundancy in the inputs and outputs to maintain digital control of the gas generator for any single input-output failure. The pressure sensors are not redundant; in the event of loss of a pressure sensor, a synthesized value is calculated. The DEEC FDA is discussed in detail in reference 9. If the digital control cannot be maintained, control is assumed by the backup control.

Backup Control (BUC) - The backup control in the DEEC system is a simple hydromechanical engine control housed in the same unit as the DEEC gas-generator fuel-metering valves. BUC operation is limited to nonaugmented power and is operable, at a reduced performance level, over the entire engine operating envelope.

\section{RESULTS OF THE DEEC FLIGHT EVALUATION}

FAULT DETECTION AND ACCOMMODATION - The experience gained through use of the DEEC FDA is of interest for the HIDEC program because the DEEC will be a key part of the HIDEC system. The DEEC design philosophy of a single-string digi-tal system with a totally dissimilar hydromechanical backup control needs to be validated.

Extensive testing has been performed on the FDA logic operation and its ability to transfer to BUC under selected failure conditions. The closed-loop bench test allowed hydromechanical and electronic components to be run while operating the engine computer simulation. This allowed testing of the FDA by intentionally introducing faults into the system without the risk of damaging an engine. Additional testing included sea-level and altitude tests and simulation testing of selected failures and result-ing accommodation process.

During the course of the DEEC flight test program, two failures were detected and accommodated. The first was a detected failure of the fan inlet total temperature (TT2) sensor, which resulted in the use of the redundant sensor and no loss in performance. The second failuxe involved the PT6M sensor, causing the nozzle trim and augmentation to be inhibited while DEEC engine control was maintained. There were no false failures detected by the DEEC and no required transfers to the BUC mode because of control system anomalies.

The PT6M failure occurred during an idle-tomaximum throttle transient at Mach 0.8 and an altitude of $30,000 \mathrm{ft}$. The PT6M signal initially failed to a value of $92 \mathrm{lb} / \mathrm{in}^{2}$, less than the upper limit of $110 \mathrm{psia}$. In response to this, the nozzle was driven open by the high PT6M signal in an attempt to accommodate the nozzle trim logic to hold EPR. When the PT6M sensor exceeded the 110 psia maximum limit, the failure was flagged and the nozzle was commanded to the basic schedule value. After the flight, the pressure sensor worked normally and the failure could not be duplicated. The DEEC unit was removed and was subjected to extensive environmental tests. It was eventually decided that contamination in the socket of a programmable read-only memory (PROM) used in the pressure sensor signal processing had caused the failure.

One of the two TT2 sensors failed following an acceleration to Mach 1.4 and an altitude of $30,000 \mathrm{ft}$. The TT2 "A" sensor had been intermittent just prior to these conditions and then became a hard failure. The TT2 fail flag was set when the sensor exceeded the $-110^{\circ} \mathrm{F}$ limit. Because the detected failure was one of the redundant sensors, no performance loss was noted during the time the sensor failed. The TT2 failure was. found to be caused by dirt on the connector at the engine-airplane disconnect. No additional occurrences of this problem have been noted. 
Because only two faults occurred in the DEEC flight evaluation, it was not possible to adequately evaluate the DEEC system operation in the synthesized parametex modes. Therefore, an additional DEEC flight investigation is scheduled to be conducted in which certain sensors can be failed. This will allow operation in the synthesized parameter modes at various points in the flight envelope (9).

NOZZLE INSTABILITY - Another area of interest for the HIDEC program is the stability of the EPR control loop. This loop will be used in the HIDEC program to vary the stall margin in response to airplane maneuvers. During the DEEC program, a nozzle instability was encountered. that revealed the sensitivity of the EPR control loop and the difficulty in evaluating it. The nozzle instability was encountered in the highaltitude, low-airspeed region of the flight envelope. The nozzle oscillated in a limit cycle with an amplitude of approximately $0.4 \mathrm{ft}^{2}$ peakto-peak at a frequency of approximately $1.5 \mathrm{~Hz}$. some nozzle overshoots and undershoots also occurred during the augmentor sequencing. The instability resulted in augmentor blowouts, caused by the low-pressure level that occurred when the nozzle was too far open, and stalls that occurred when the nozzle was too far closed. An example of a stall that occurred as a result of nozzle instability following an idle-tomaximum throttle transient at 175 knots and an altitude of $45,000 \mathrm{ft}$ is shown in figure 6 . The nozzle oscillation built up over a period of four cycles and the high-pressure level backpressured the fan, causing a stall.

In other instances, the oscillation began, damped out, and began again, indicating a marginal stability in the nozzle control loop. The oscillation only occurred at augmented power, not at intermediate powex. As shown in figure 5 , the nozzle is controlled to maintain the desired engine pressure ratio (EPR). During the DEEC design and initial evaluation, the stability of the EPR control loop was evaluated and found to be adequate, based on simulation results. During flight clearance testing at Arnold Engineering and Development Center, the EPR loop stability of the DEEC flight test engine was evaluated at low-airspeed and high-altitude conditions, but only at intermediate power. The nominal EPR loop gain was doubled and no instability was noted. Because the altitude test results on the flight engine did not indicate a problem, the full, nonlinear, aerothermodynamic F100 engine simulation was used to investigate the instability. The simulation could not be made to duplicate the results observed in flight.

To more exhaustively investigate the causes of the EPR control loop nozzle instability, an altitude test program was performed at the NASA Lewis Research Center. The F100 XD-11 engine used for this test did not exhibit any nozzle stability problems when operating with its normal control gain settings. Thus the DEEC breadboard was used to provide variable gain and other control modifications. During the program it was found that an increase in integral control gain could cause the nozzle to become oscillatory at a Mach 0.6 and 45,000-ft altitude condition (fig. 7). Figure $7(a)$ is a plot that is representative of the type of results obtained with the integral gain 2.5 times nominal. This figure shows that there are lightly damped

$1.4 \mathrm{~Hz}$ oscillations ( $r$ inging) of $\pm 0.1 \mathrm{ft}^{2}$ amplitude when a small step change in EPR command is initiated and removed. Figure $7(b)$ shows this result more dramatically for an integral gain increase to 3.5 times nominal. In both of these cases, the oscillations damped within a few seconds. These results were obtained with the deadband element in the EPR control loop set to zero. This resultant instability, produced by the increased integral gain, does not demonstrate the sustained oscillations of the flight test results. It indicates there are probably mechanical differences between the $\mathrm{XD}-11$ and the flight test engines in areas such as friction, rigging tolerances, and wear. The important fact is that the frequencies of oscillation are very close, indicating comparable linear dynamic properties. This fact makes further analysis of the data meaningful. Frequency response data were also obtained during the altitude tests by inserting step and sine wave commands in nozzle area, and the transfer functions were determined.

With the results of the NASA Lewis tests, it was practical to improve the engine simulation. The engine manufacturer conducted a linear system analysis of the EPR control loop using the transfer functions from the Lewis tests, and found that the loop had very marginal stability at high-altitude and low-airspeed conditions. It was proposed to cut the EPR loop gain in half and to incorporate a larger deadband in the loop to increase its stability.

To further investigate the nozzle instability, Ames-Dryden developed a nonlinear digital simulation of the EPR control loop, incorporating the transfer functions developed from the NASA Lewis test data and the engine manufacturer's linear analysis. A block diagram of the simulation is shown in figure 8. It models the part of the EPR control loop of figure 5 that is enclosed in the dashed lines. The EPR request is input, is passed through a deadband, and then goes to integral and proportional gains to generate the EPR request. This is converted to a nozzle area request, which is input into a nozzle dynamics block. This block includes nozzle rate limiting and hysteresis. The nozzle output is used to generate the appropriate EPR output for the particular flight condition, the AJ/EPR transfer function having been determined from the NASA Lewis tests results. The resulting EPR is fed back through the DEEC pressure sensors, the DEEC digital filtex, and DEEC computation cycle time to generate the DEEC EPR feedback. Another feedback loop must also be considered. As the nozzle area and EPR change, the fan rotor speed (N1) responds. As noted in figure 5, N1 is an input to the ERR request logic. The $A J / N 1$ transfer function was derived 
from Lewis test data. The N1-to-EPR constant is the slope of the table used by the DEEC logic in computing the EPR request.

The simulation was mechanized in the time domain using $z$-transform techniques. The digital computex program used an integration interval of 0.005 sec, and modeled the DEEC computational cycle time of 0.02 sec. A step input in EPR request was used to evaluate the EPR loop stability.

Results of the Ames-Dryden nonlinear EPR loop simulation are shown in figure $9(a)$ for a Mach 0.6 and 45,000-ft filight condition. The simulation results show a limit cycle with very similar frequency and magnitude to the nozzle oscillation observed in flight. This nonlinear simulation, which incorporated the NASA Lewis test results, essentially duplicated the flight results, whereas the engine manufacturer's full nonlinear simulation did not predict the oscillation. This points out the importance of having high-quality engine modeling data. Pxoposed logic changes for the DEEC sof tware were evaluated on the Ames-Dryden simulation. As shown in figure $9(b)$, when the deadband was increased and the integral gain was cut in half, the response to the same step input in EPR request produced only a small overshoot that rapidly damped. This response was judged to be acceptable.

The next phase of the DEEC flight evaluation showed no evidence of nozzle instability. The lower EPR loop gains also reduced the number of nozzle overshoots that occurred during augmentor sequencing, and that reduced the number of blowouts that occurred during augmentor transients.

The sensitivity of the EPR loop to system dynamics points out the need for high-quality engine data in the engine simulation and the need to adequately model the nonlinearities.

AUGMENTED THROTTLE TRANSIENTS - The largest part of the DEEC flight evaluation involved the investigation of the augmentor transient capability. The standard F100 engine has encountered occasional stalls and blowouts during throttle transients, and one goal of the DEEC program was to minimize these problems. At the end of the DEEC phase 2 flight evaluation, numerous stalis and blowouts had been experienced. In the phase 3 evaluation, modifications were evaluated, and significant improvements were found. The primary goal of phase 4 was to evaluate the augmentor transient performance with the LOD and additional improvements to the logic.

Figure 10(a) summarizes the military-tomaximum transients for phase 4 , and shows that all transients were successful at altitudes up to $50,000 \mathrm{ft}$. Additional tests were performed at altitudes above 50,000 $\mathrm{ft}$ to determine the upper limit of successful operation. One nonrecoverable stall occurred at $52,000 \mathrm{ft}$ at 175 knots, but all other tests were successful. Success boundaries for the standard F100 engine and for the DEEC engine during phases 2 and 3 are also shown.

The idle-to-maximum power throttle transient summary is shown in figure $10(b)$. All the attempted transients were successful, al though some PLA recycles were required. No stalls occurred. Again, the success lines for the standard F100 and the previous DEEC tests and the F-15 envelope are shown. The DEEC phase 4 results provide full augmentor capability to the edge of the envelope, which is an improvement of almost 15,000 ft over tests using the standard F100 engine.

\section{F100 EMD ENGINE EXPERIENCE}

The F-15 airplane powered by the F100 EMD engines has a very high thrust-to-weight ratio representative of future aircraft such as the advanced technology fighter. For this reason, it is a good airplane to investigate the benefits of integrated flightpath management. In addition, the operability of the engine and the DEEC operation on the engine are of interest for HIDEC.

AIRPLANE PERFORMANCE - Performance evaluations consisted of intermediate and maximum power aircraft accelerations at altitudes of $5,000,10,000,30,000$, and 40,000 ft. With one F100 EMD engine and one F100-PW-100 engine installed in the F-15 airplane, the time to accelerate at maximum power from Mach 0.8 to Mach 2.0 at an altitude of $40,000 \mathrm{ft}$ was reduced by 7.4 percent compared to the time with two F100-PW-100 engines installed in the aircraft. The acceleration time with two F100 EMD engines was 23 percent faster than with two F100-PW-100 engines. With two F100 EMD engines installed, the F-15 airplane is capable of sustained supersonic flight at intermediate power. At 40,000 ft, the sustained Mach number was 1.15 . THRUST RESPONSE - Throttle response of the F100 EMD engine was evaluated for formation flying and aerial refueling capability. The flight condition of $10,000 \mathrm{ft}$ and 400 knots was selected to be representative of a tactical situation. The task was wing station keeping on the lead aircraft for perturbed and nonperturbed conditions and modest manuevering. At this flight condition, station keeping for even nonperturbed tasks received a Cooper-Harper pilot rating of 6 to 8 (indicating improvement was needed). A flight condition of $25,000 \mathrm{ft}$ and 300 knots was selected to be representative of aerial refueling. Again, large lags or delays were evident between throttle and thrust response as shown in figure 11. Thrust response lagged the throttle by nearly $180^{\circ}$. The excessively slow response was caused by logic in the DEEC that was designed to increase the compressor stall margin during bodie throttle transients. This logic had been incorporated without regard to $i$ ts effect on thrust response. An additional factor was the lack of a quantitative criteria for throttle response. Once the problem became evident, a software change was incorporated into the DEEC, which improved the throttle response; subsequent Cooper-Harper ratings of 3 to 4 (indicating adequate response) were then obtained for the same flying tasks. 
DEEC PERFORMANCE - The DEEC logic, developed for the F100-PW-100 engine, was modified for the F100 EMD. The closed-loop logic operated successfully on the new engine with a minimum of changes. The DEEC flexibility was demonstrated when operability problems such as poor throttle response were solved by control logic changes (7).

\section{THE HIDEC SYSTEM}

A block diagram of the HIDEC system on the F-15 airplane is shown in figure 12. The various digital systems on the airplane can communicate with each other by way of a digital interface and bus controller. This unit permits the HIDEC system to communicate with the equipment on the F-15 H009 data bus, the universal asynchronous receiver transmitter (UART) data bus, and the 1553 bus.

The DEEC controllers on each engine communicate with the HIDEC system by way of the UART bus. The normal throttle inputs to the DEEC controllers and the backup engine controls from the cockpit are maintained.

The digital electronic flight control system (DEFCS) is a digital implementation of the analog control augmentation system (CAS) currently on the F-15 airplane. It is a dual-channel, fail-safe, high-authority system that operates in conjunction with a mechanical flight control system. The DEFCS replaces the analog computations in the CAS and has data bus input and output capability in Military-Standard (MIL-STD)

1553 format. It is programmable in higher-order language and currently has 80-percent excess capacity available for other control computations. For the early phases of the HIDEC program, the HIDEC control laws will be implemented in the unused portion of the DEFCS computers.

Initially, the pilot will communicate with the HIDEC system through a cockpit control and display panel. Later, a cockpit multifunction display will be added. This unit, which is currently produced for the F-18 airplane, communicates on the 1553 bus. The pilot's normal stick, rudder, and throttle inputs will be handled as they are in the standard F-15 airplane.

The NASA uplink system is also MIL-STD 1553compatible, and can be used to provide data to the HIDEC system. This will permit control algorithms to be processed in a ground-based computer, if desired.

Most of the airframe data required by the HIDEC system are available from the equipment currently installed and communicating on the F-15 H009 data bus, shown at the top of figure 12. Included is the air data computer, the inertial navigation set, the horizontal situation indicator, the attitude and heading reference set, and the central computer unit.

For future system expansion, an additional onboard computer can be added. This computer will be 1553-compatible, and will provide additional flexibility and computational power. The NASA data system will monitor parameters on the 1553 bus, as well as other parameters that are recorded directly. This data will be recorded onboard and also telemetered to the ground for real-time display, analysis, and use in control-law computations that may be uplinked to the airplane.

F100 EMD SIMULATIONS - Two computer simulations of the F100 EMD engine are being used in the HIDEC program - a full aerothermal steadystate engine performance program and a linear state-variable dynamic engine model. The steadystate model provides accurate values for many engine parameters including engine thrust, fuel. flow, fan and core stall margins, and the DEEC parameters. Its inputs are inlet pressure, temperature, and power setting.

The linear state-variable dynamic model of the F100 EMD engine provides reasonably realistic dynamic response characteristics for engine transients but less accurate steady-state results. The linear models are determined at several points in the flight envelope and for several power settings, and linear interpolation is used between the modeled conditions.

ADAPTIVE ENGINE CONTROL SYSTEM MODE - A simplifed view of the adaptive engine control system (ADECS) mode is shown in the block diagram of figure 13. Airframe data are used to provide not only the current angles of attack and sideslip, but also a prediction of what these parameters will be in the future. These inputs are then used to determine current and predicted inlet distortion. The inlet distortion and the engine's current stall margin is then used to generate an uptrim command. The uptrim command can be small if the distortion is near the engine's tolerance, or it can be large if the distortion is very low or if the engine's stall margin is very high. The uptrim command will be converted into DEEC commands and then be transmitted to the DEEC, which will move the engine variables to effect the uptrim. The many engine parameters from the DEEC will be used to determine the remaining engine stall margin, and the calculated engine airflow will be fed back to the inlet distortion calculation. Each of these functions is discussed in more detail in reference 8 .

ADECS PREDICTED RESULTS - The performance gains caused by the ADECS mode uptrim have been investigated for the HIDEC program. The F100 EMD steady-state performance deck has been used to determine the effects of EPR uptrim at several flight conditions. Figure 14 shows the thrust increase predicted for straight-and-level flight, with values ranging from 2 to 8 percent.

The dynamics of the uptrim and downtrim processes have been investigated with the linear state-variable dynamic model. Results show that uptrims of up to 10 percent can be removed in less than 1 sec without any overshoots in thrust or stall margin.

FLIGHTPATH MANAGEMENT MODE - The other mode to be implemented in the HIDEC program is the integrated flightpath management mode. Figure 15 shows some of the potential flightpath management modes that can be investigated in the HIDEC program. These include the trajectory. 
optimization routines that provide optimizations for minimum time and fuel and maximum range and endurance. Later, these can be expanded to include optimum intercepts, four-dimensional navigation, and terrain-following-terrain avoidance routines. Optimal evasive maneuvers can then be considered, finally leading to concepts for automated air combat.

Initially, the trajectory optimization modes will be implemented and used as the basis for evaluating the performance improvements that result from the ADECS control mode. A simple example of such an energy management mode is a minimum time flightpath.

\section{CONCLUDING REMARKS}

The Dryden Flight Research Facility of NASA Ames Research Centex has conducted several propulsion control programs that have contributed to the highly integrated digital electronic control (HIDEC) program. The digital electronic engine control (DEEC) flight evaluation investigated the performance and operability of the F100 engine equipped with a full-authority digital electronic control system. Investigations of nozzle instability, fault detection and accommodation, and augmentor capability were accomplished. The F100 engine model derivative (EMD) program showed significant improvement in airplane performance. A throttle response problem was found and solved with a software revision to the control logic. For the HIDEC program, the F100 EMD engines equipped with DEEC controls will be integrated with the digital flight control system. The control modes to be implemented are an integrated flightpath management mode and an integrated adaptive engine control system mode.

\section{NOMENCLATURE}

ADECS adaptive engine control system

ADEN augmented deflector exhaust nozzle

AJ jet primary nozzle area, $f t^{2}$

backup control

CAS control augmentation system

CENC convergent exhaust nozzle control

CIVV compressor inlet variable vane

D distortion

DEEC digital electronic engine control

DEFCs digital electronic flight control sys tem

DT

distortion tolerance

EMD engine pressure ratio, PT6M/PT2

FA-AB afterburner fuel-air ratio

FDA

FTIT

GG

HIDEC

HIMAT

HP.

IPCS

LOD

M

N1

N2

PAB

PB

PLA

PLA-AB

PROFIT

PROM

PT2

PT6M

RCVV

TT2

UART

VC

WA

WF

WFGG

$\alpha$

B fault detection and accommodation

fan turbine inlet temperature, deg $F$

gas generator

highly integrated digital electronic control

highly maneuverable aircraft technology

pressure altitude, ft

integrated propulsion control system

light-off detector

Mach number

fan rotor speed, rpm

core rotor speed, rpm

augmentor static pressure, $1 \mathrm{~b} / \mathrm{in}^{2}$

burner pressure, $1 \mathrm{~b} / \mathrm{in}^{2}$

power lever angle, deg

afterburner power levex angle, deg

propulsion-flight control integration technology

programmable read-only memory

fan inlet static pressure, $1 \mathrm{~b} / \mathrm{in}^{2}$

fan inlet total pressure, $1 b / i^{2}$

turbine discharge total pressure, $1 b / \mathrm{in}^{2}$ (mixed core and fan stream)

rear compressor variable vane

fan inlet total temperature, $\operatorname{deg} F$

universal asynchronous receiver transmitter

calibrated airspeed, knots

airflow

fuel flow, $1 \mathrm{~b} / \mathrm{hr}$

gas-generator fuel flow, lb/hr

angle of attack, deg

angle of sideslip, deg 
$\Delta$

change

Superscript:

$\wedge$

estimate

\section{REFERENCES}

1. Burcham, Frank W., Jr॰; and Batterton, Peter G.: Flight Experience With A Digital Integrated Propulsion Control System on an F-111E Airplane. AIAA Paper 76-653, June 1976.

2. Reukauf, Paul J.; and Burcham, Frank W., Jr.: Propulsion System/Flight Control Integration for Supersonic Aircraft. NASA CP-001, 1976.

3. Burcham, Frank $W_{\bullet}, J_{\bullet}$ : "Propulsion-Flight Control Integration Technology," Active Controls in Aircraft Design. AGARD-AG-234, Nov. 1978, pp 7-1 to 7-9.

4. Burcham, Frank $W_{\bullet}, J_{\bullet} ;$ and Stewart, James F.: The Development Process for Integrated Propulsion Flight Controls. NASA CP-2162, 1980.
5. Baer-Riedhart, Jennifer L.: The Development and Flight Test Evaluation of an Integrated Propulsion Control System for the HiMAT Research Airplane. AIAA Paper 81-2467, Nov. 1981 .

6. Burcham, Frank W., Jr॰; Myers, Lawrence $\mathrm{P}_{\bullet}$; and Walsh, Kevin R॰: Flight Evaluation Results for a Digital Electronic Engine Control in an F-15 Airplane. NASA TM-84918, 1983.

7. Myers, Lawrence $P_{\bullet} ;$ and Burcham, Frank W., Jr.: Preliminary Flight Test Results of the F100 EMD Engine in an F-15 Airplane. NASA TM-85902, 1984 .

8. Burcham, Frank $W_{\bullet}, J r_{\bullet}$; and Haering, Edward $A_{\bullet}, J r_{0}:$ Highly Integrated Digital Engine Control system on an F-15 Airplane. NASA TM-86040, 1984 .

9. Baer-Riedhart, Jennifer L。: "Digital Electronic Engine Control Fault Detection and Accommodation Flight Evaluation," Digital Electronic Engine Control (DEEC) Flight Evaluation in an F-15 Airplane. NASA CP-2298, 1984, pp 107-126.

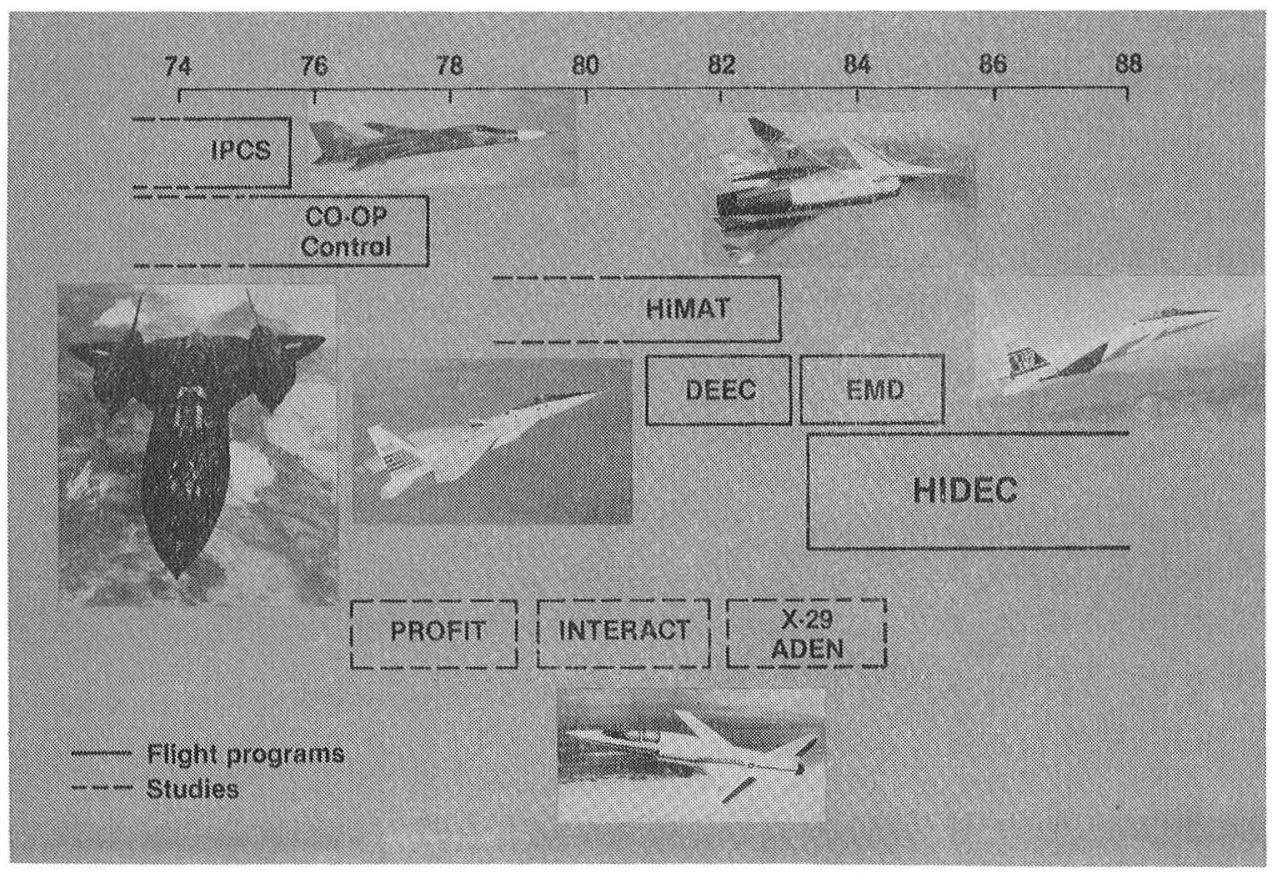

Figure 1. NASA Ames-Dryden digital propulsion control programs. 


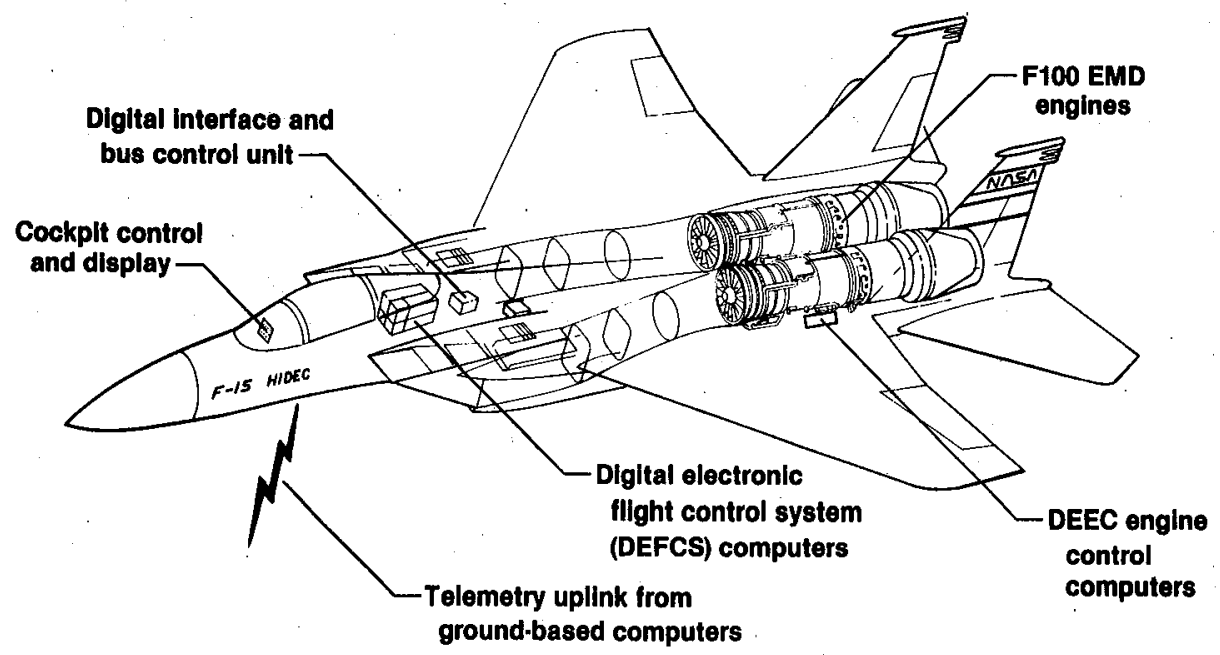

Figure 2. Features of the F-15 HIDEC research airplane.

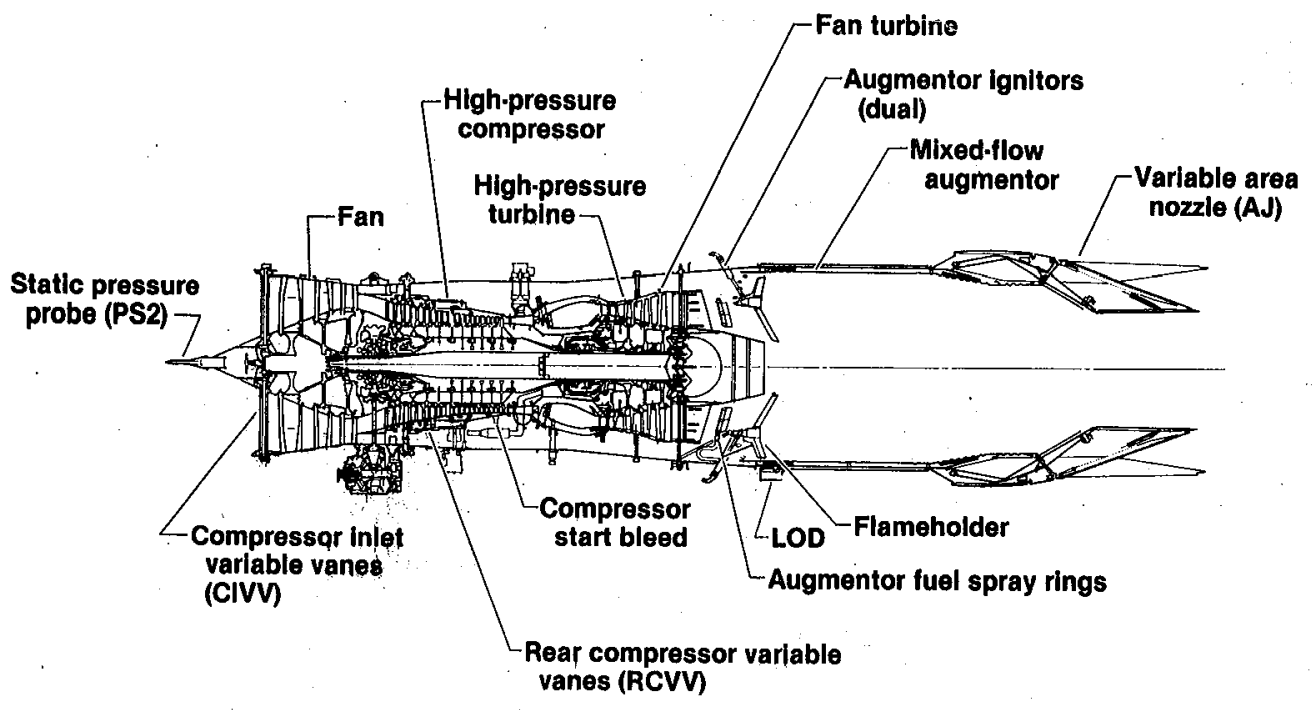

Figure 3. Section view of the F100 engine. 


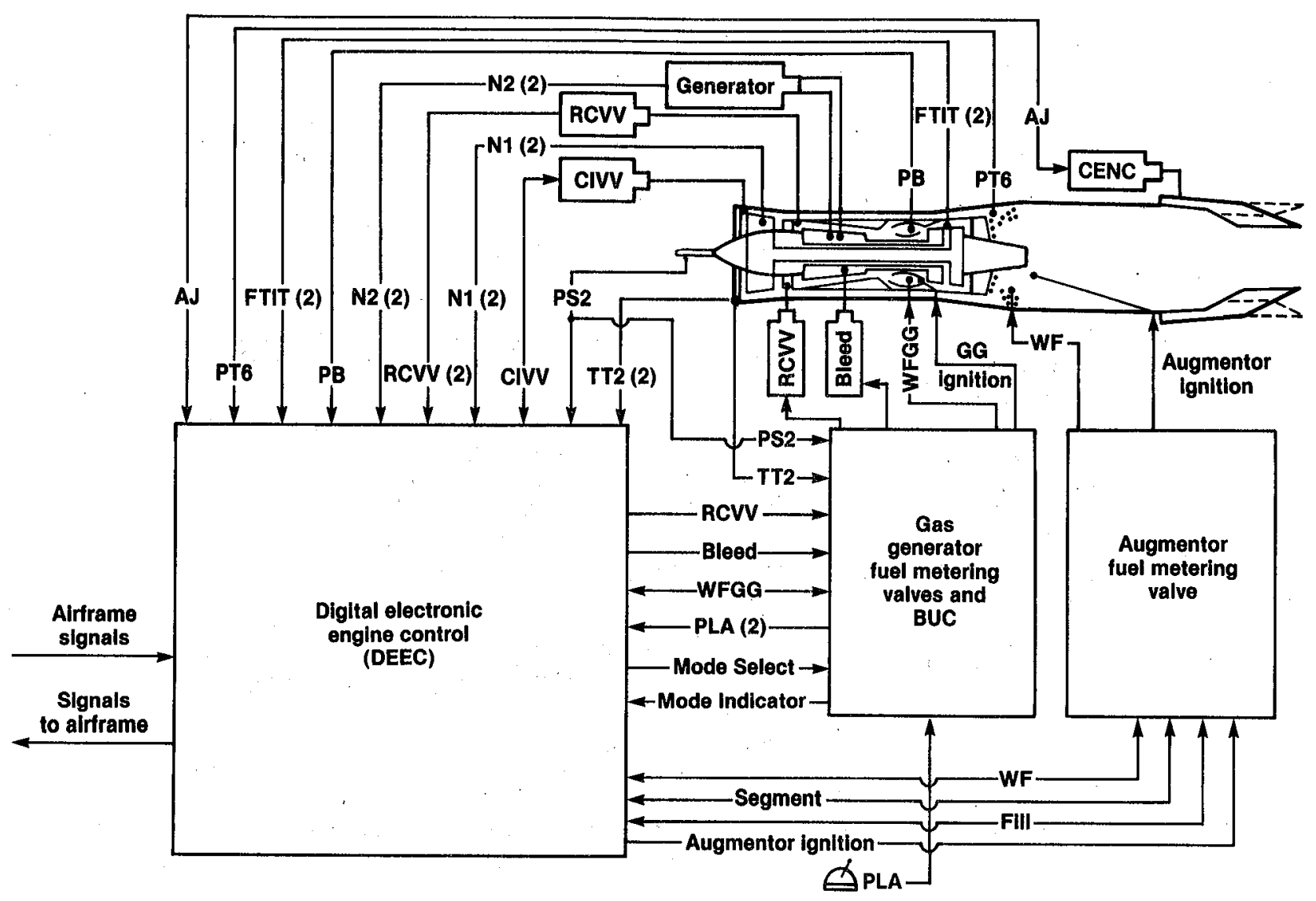

Figure 4. Diagram of the DEEC system.

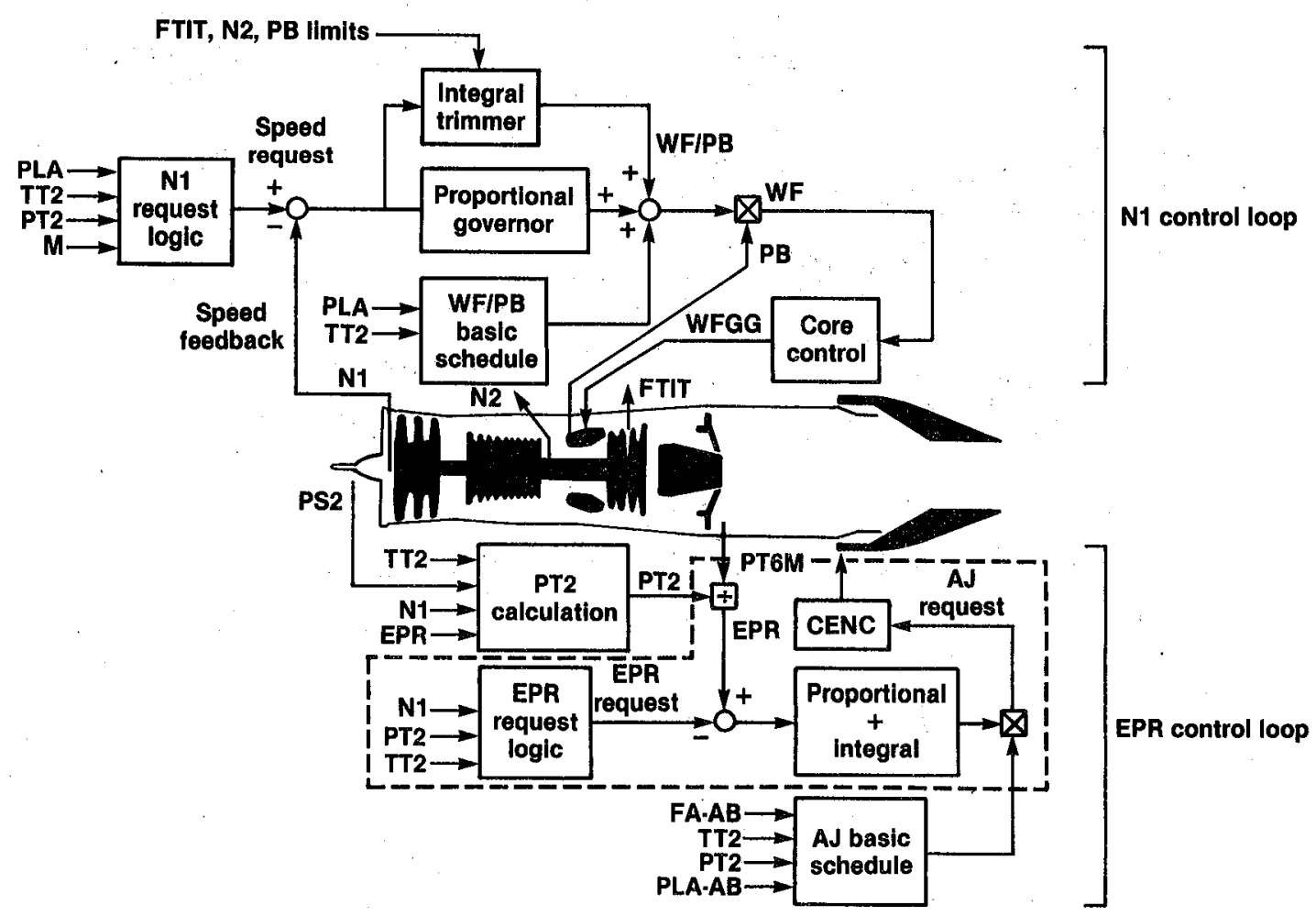

Figure 5. The DEEC modes for fan rotor speed and engine pressure ratio. 

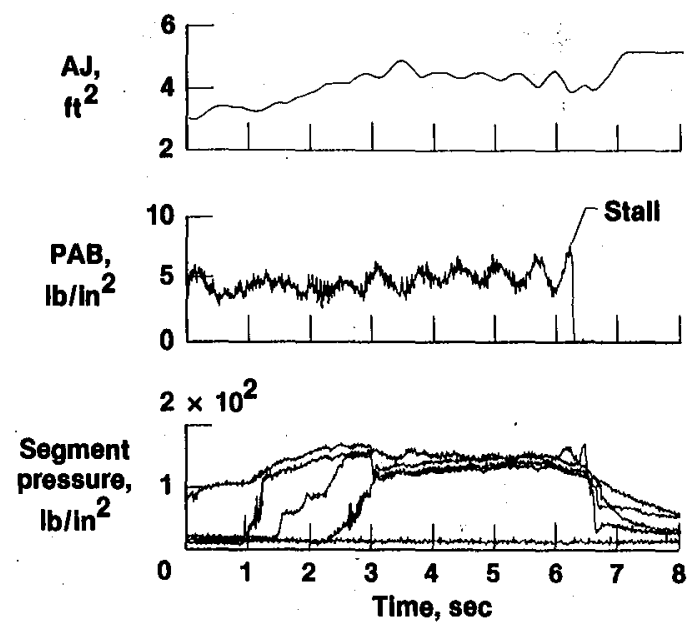

Figure 6. Time history of an idleto-maximum power throttle transient In which nozzle instability caused a stall. $V C=175$ knots, HP

$=45,000 \mathrm{ft}$.

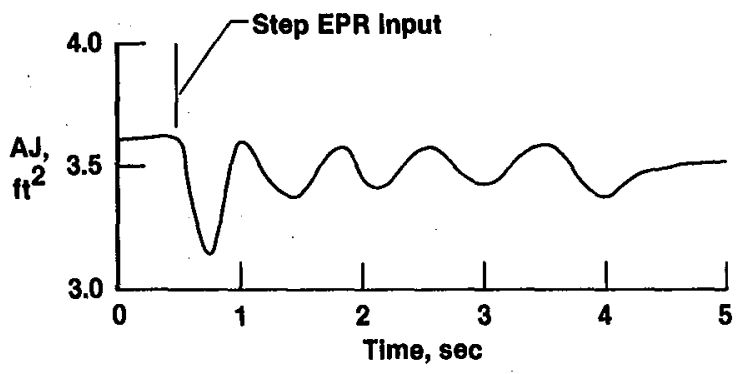

(a) Integral gain 2.5 times nominal.

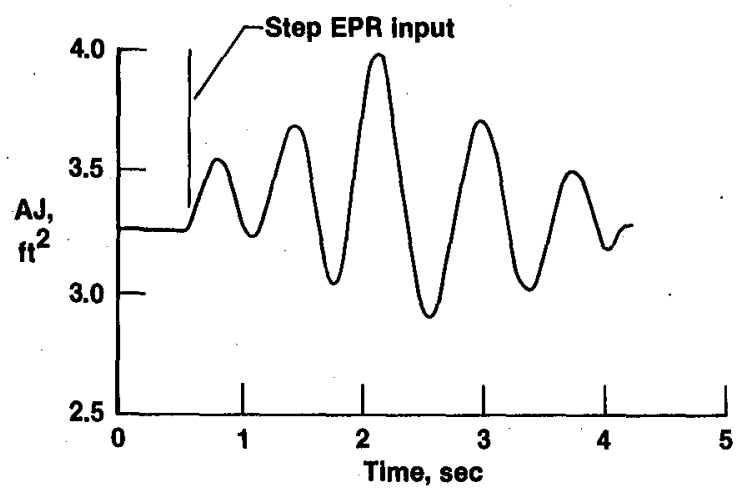

(b) Integral gain 3.5 times nominal.

Figure 7. Time history of nozzle response to step inputs in EPR, NASA Lewis tests of $X D-11$ engine. $H P=45,000 \mathrm{ft}, M=0.6$.

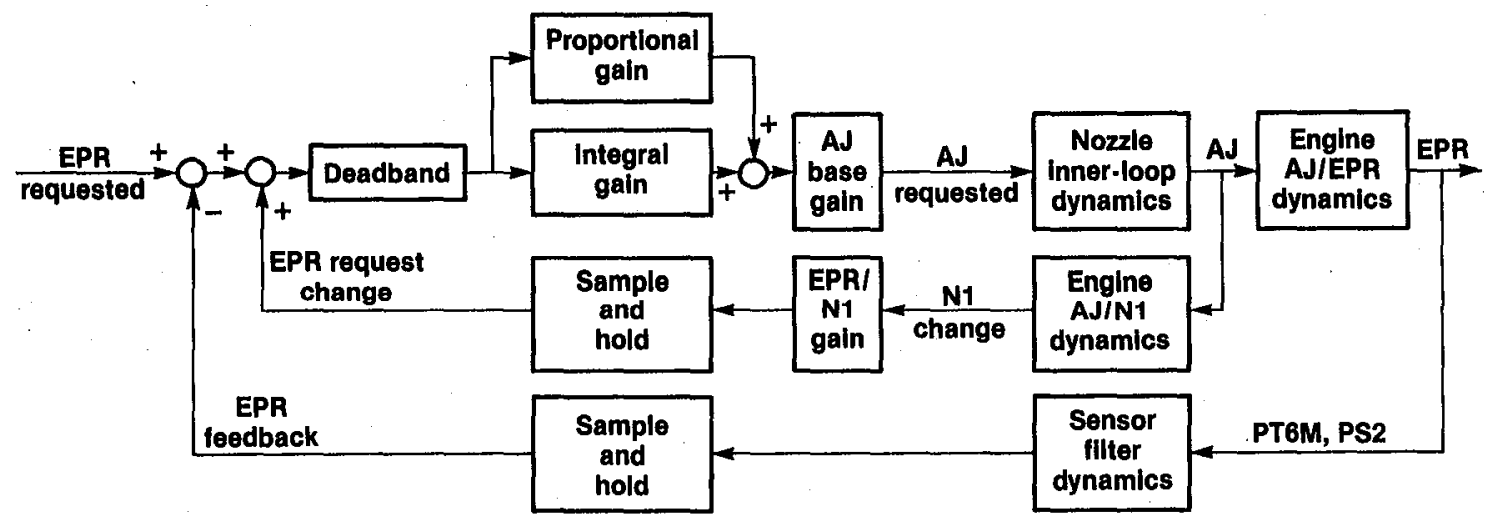

Figure 8. Block diagram of the DEEC nonlinear digital nozzle simulation. 


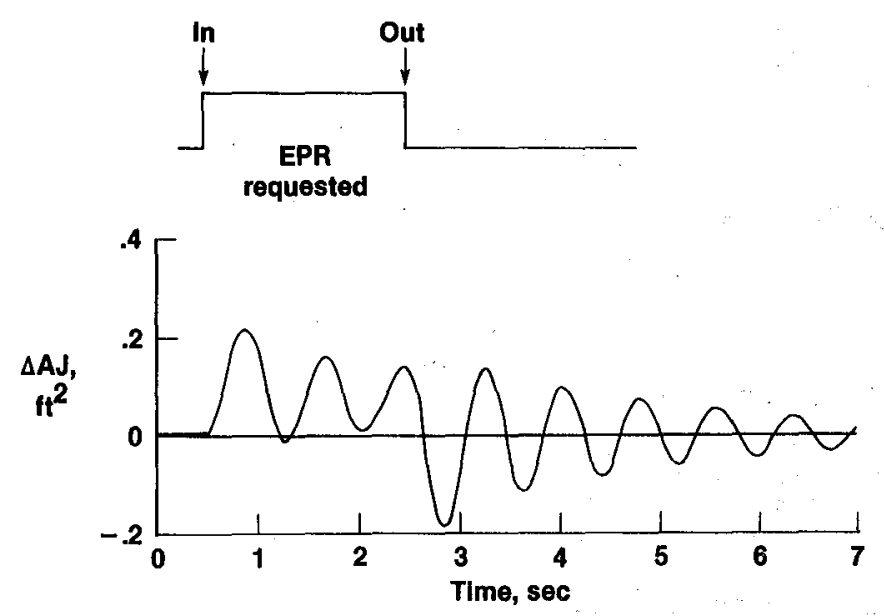

(a) Phase 2 control logic.

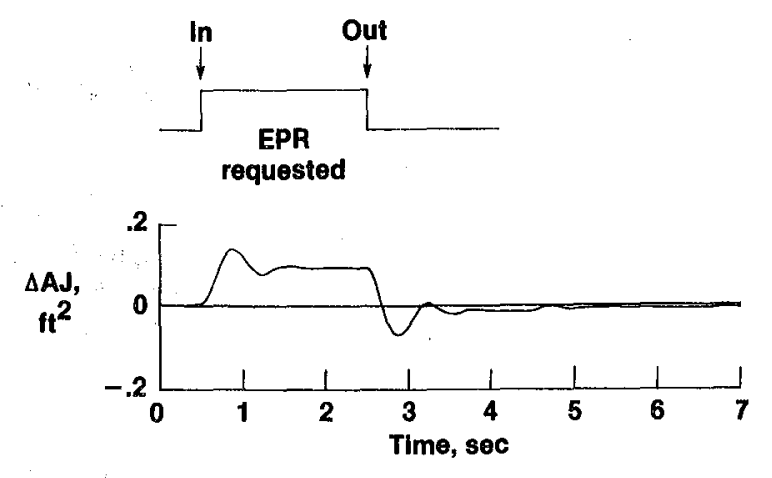

(b) Phase 3 control logic.

Figure 9. DEEC nonlinear nozzle simulation results. $M=0.6, H P=45,000 \mathrm{ft}$.

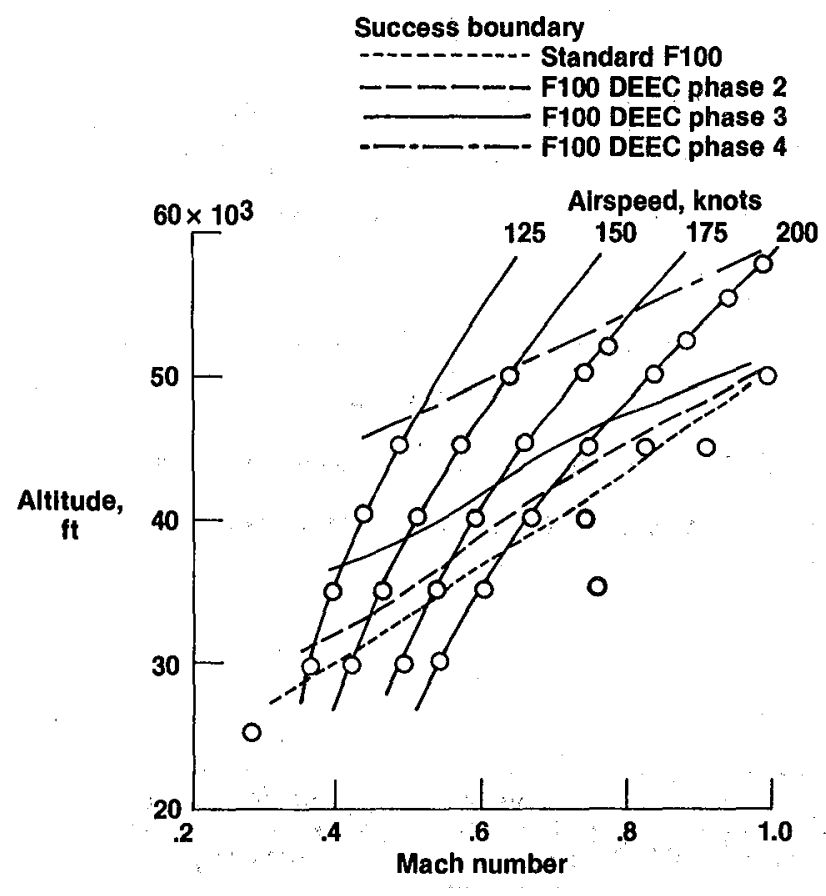

(a) Idle-to-maximum power.

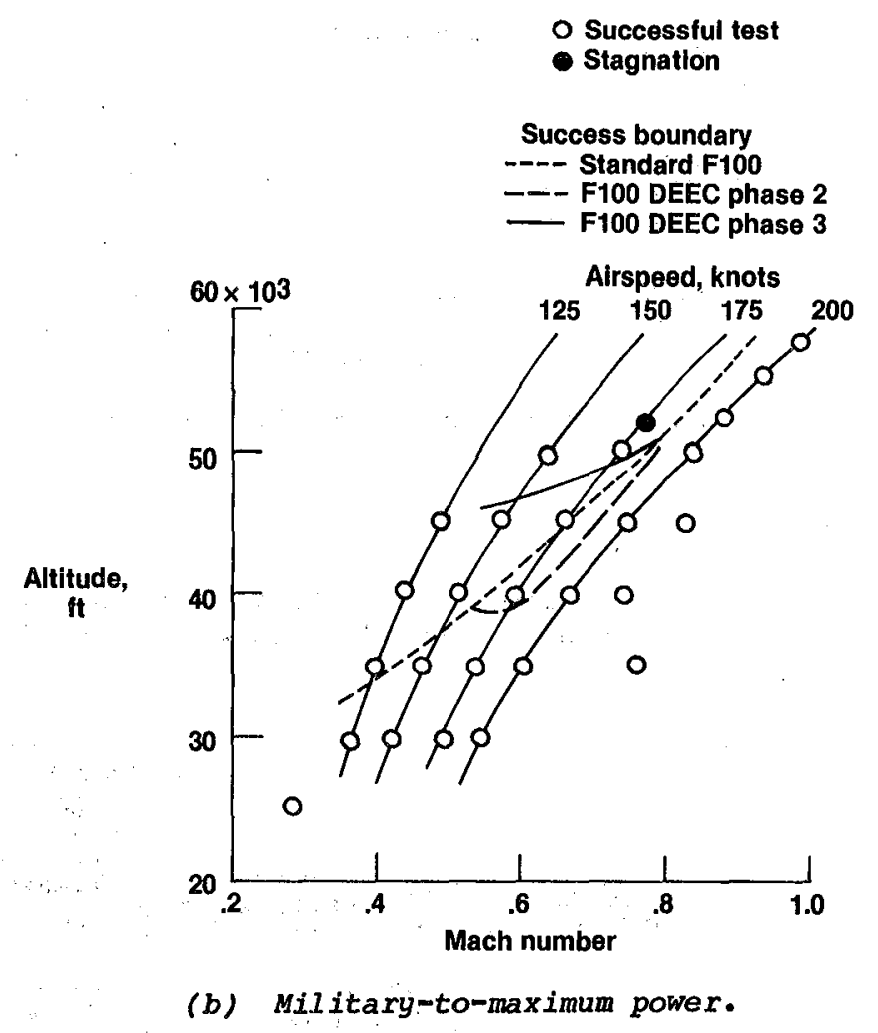

O Successful tes Stagnation

Success boundary

Standard F

100 DEEC phase 2 Airspeed, knots

Figure 10. Summary of DEEC augmentor throttle transient capability. 


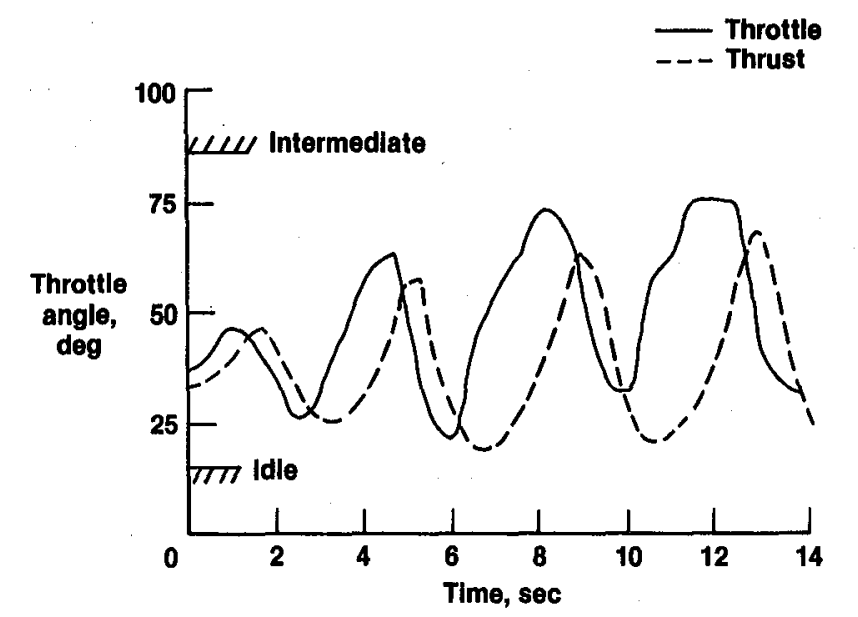

Figure 11. Thrust response to throttle cycling during close formation flying.
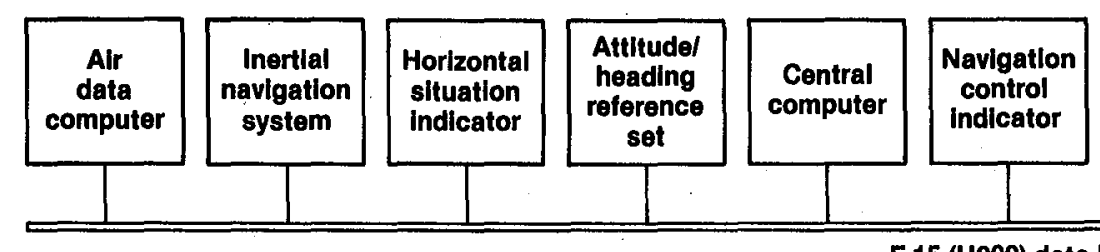

MIL 1553 data bus

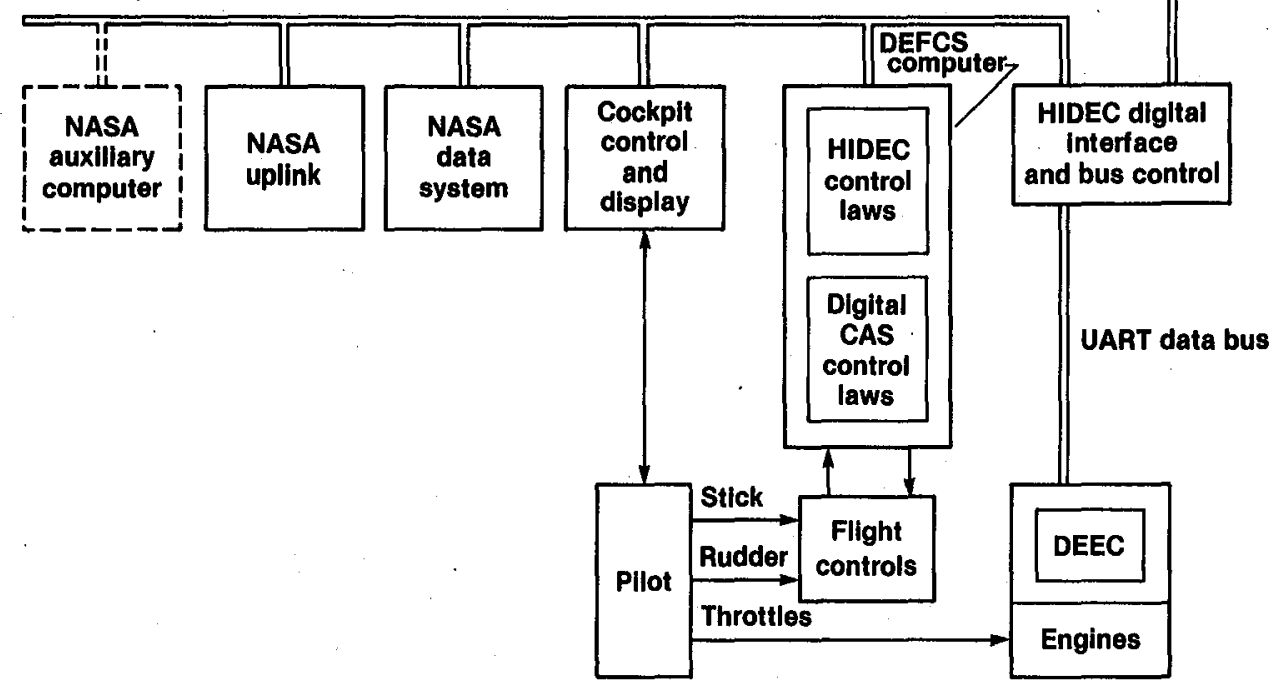

Figure 12. Block diagram of the HIDEC system. 


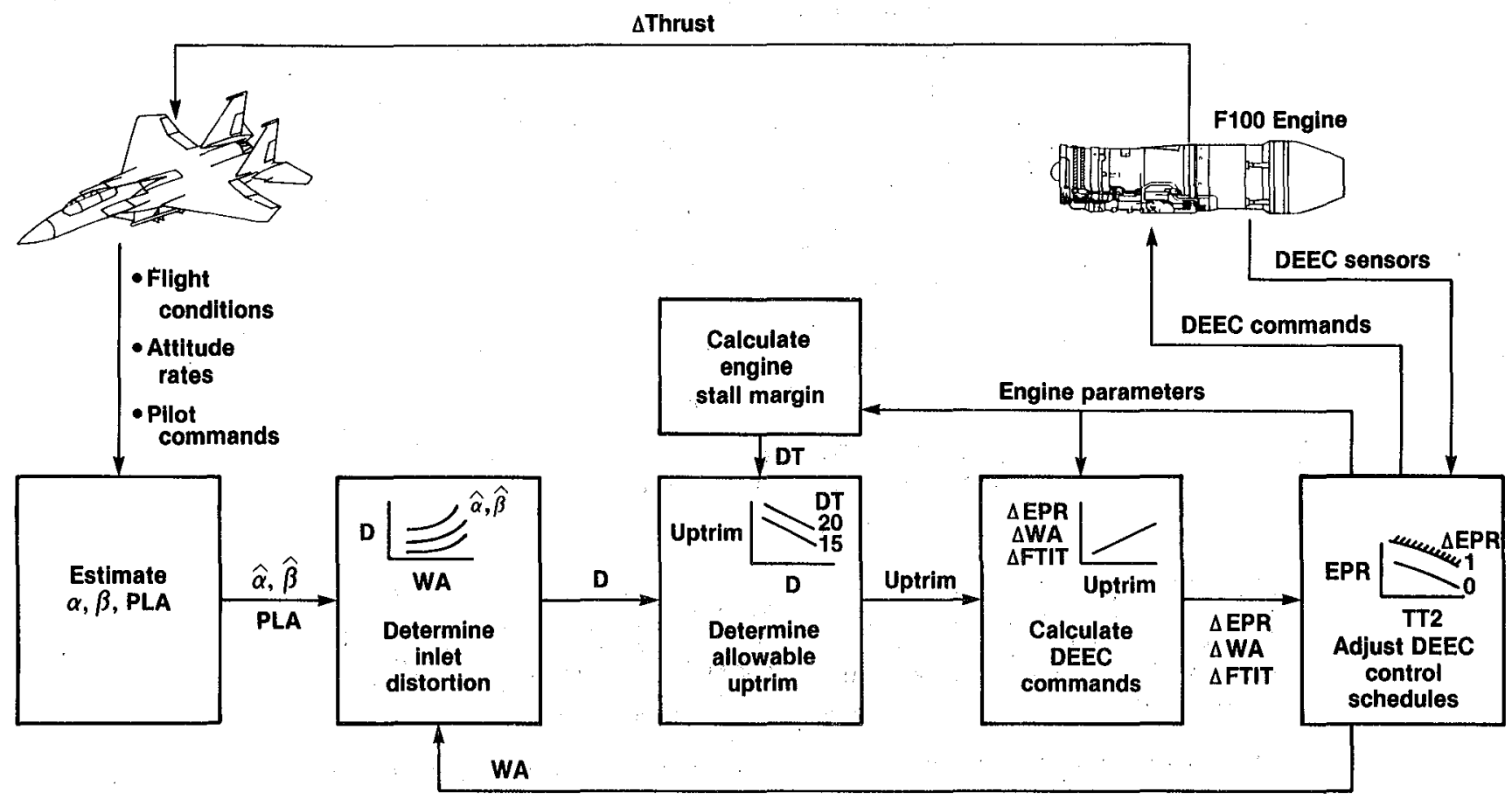

Figure 13. Block diagram of the HIDEC adaptive engine control system mode.

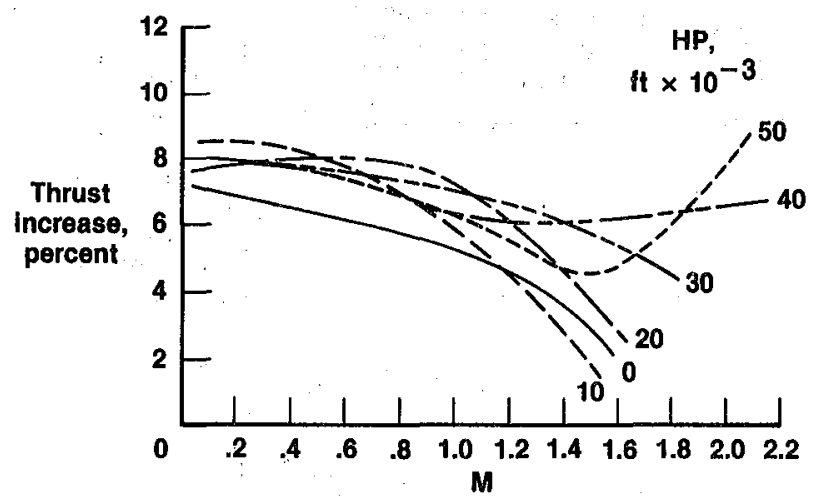

Figure 14. Predicted ADECS mode thrust increase for the F100 EMD engine. 


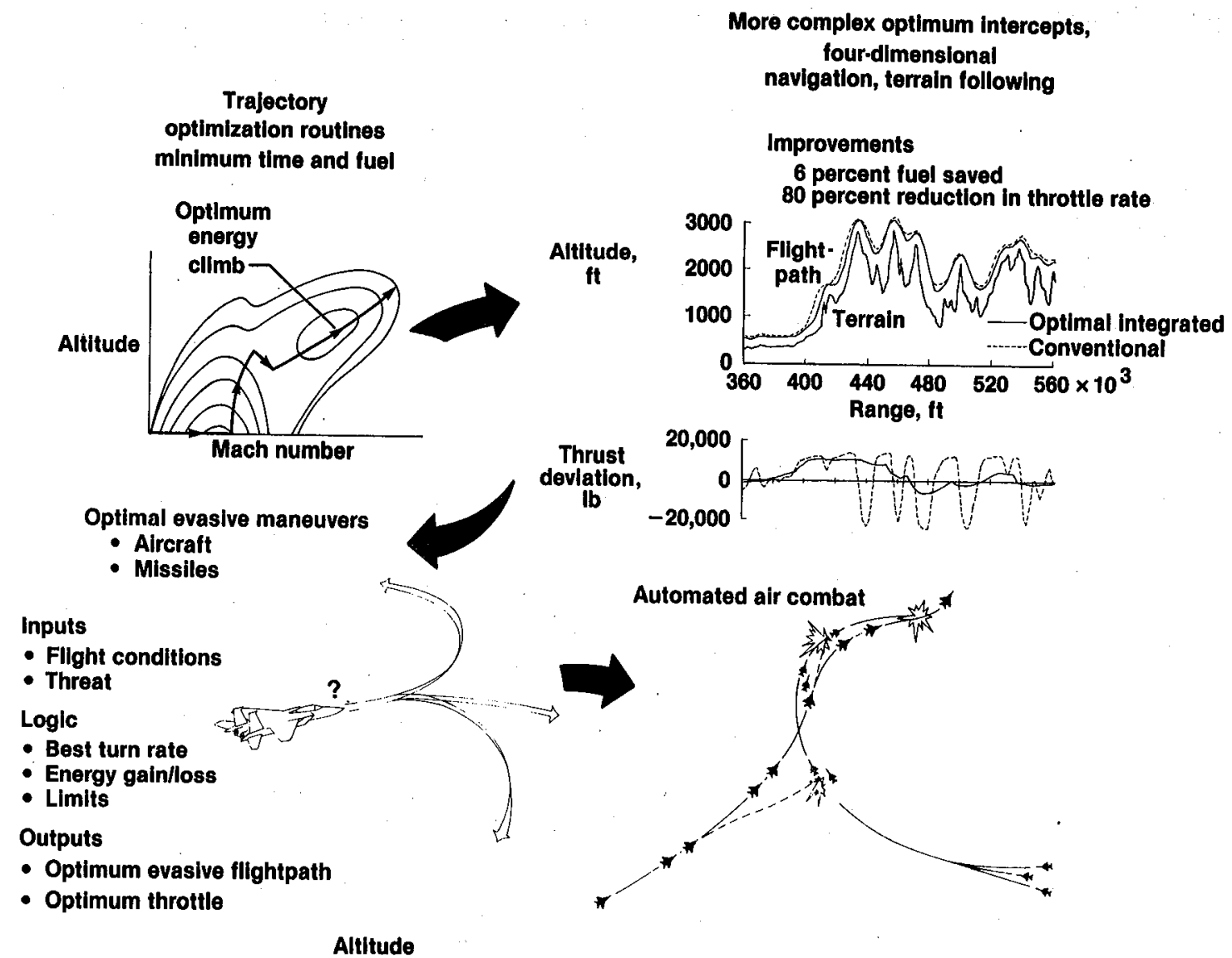

Figure 15. Integrated flightpath management modes for the HIDEC program. 


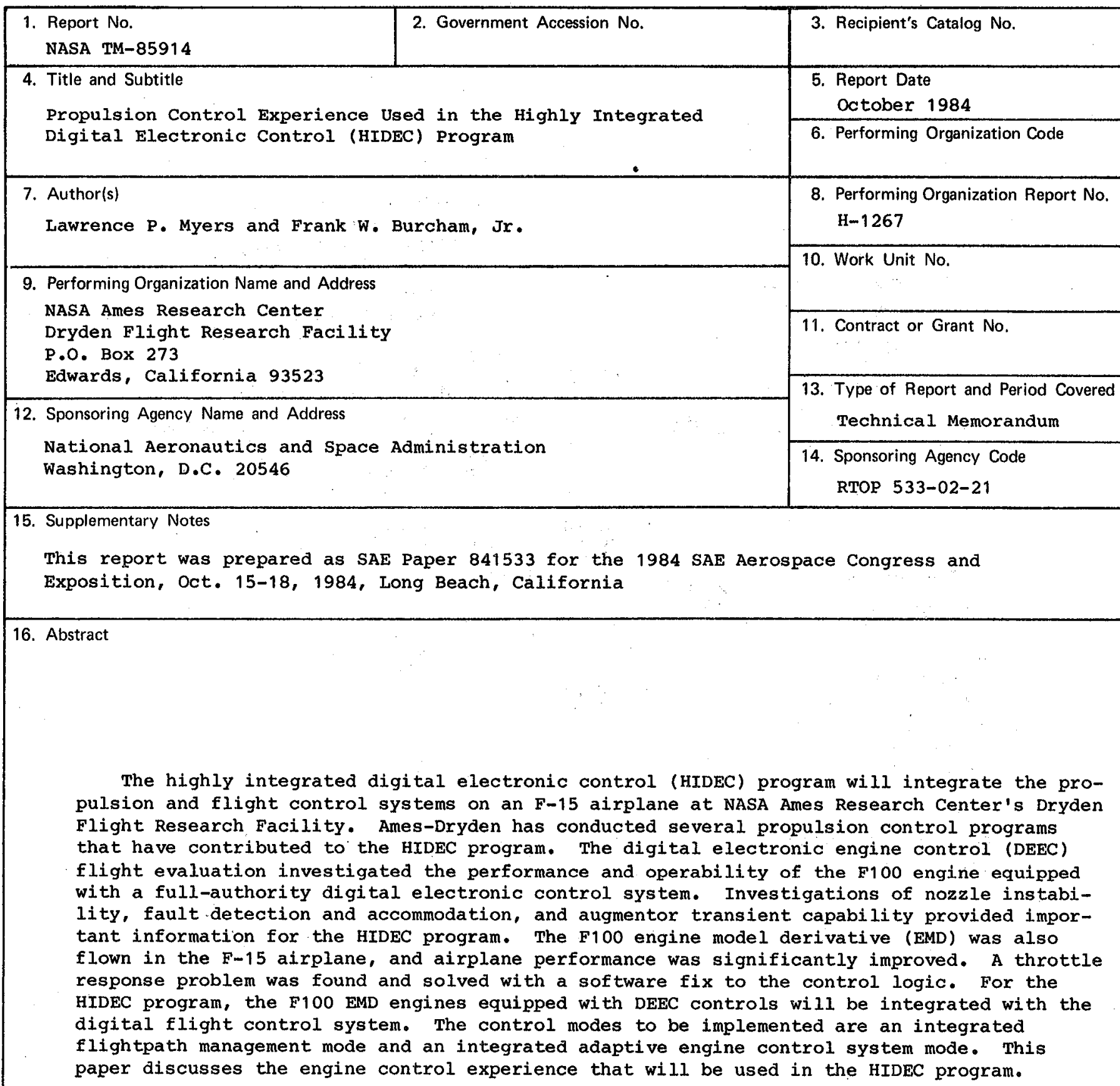

17. Key Words (Suggested by Author(s))

Advanced F100 engine; digital electronic engine control (DEEC); integrated control; flightpath management; adaptive engine stall margin; increased thrust; improved operability; flight test; F-15 aircraft

19. Security Classif. (of this report) Unclassified
20. Security Classif. (of this page) unclassified
18. Distribution Statement

Unclassified-Unlimited
STAR category 07 
